Intecoms: Journal of Information Technology and Computer Science

Volume 1 Nomor 2, Desember 2018

e-ISSN : 2614-1574

p-ISSN : 2621-3249

DOI : https://doi.org/10.31539/intecoms.v1i2.433

\title{
SISTEM APLIKASI SARANA PRASARANA PERGURUAN TINGGI MENGGUNAKAN TEKNOLOGI NEAR FIELD COMMUNICATION BERBASIS ANDROID
}

\section{HIGHER EDUCATION INFRASTRUCTURE SYSTEM USING NEAR FIELD COMMUNICATIONBASED ON ANDROID}

\author{
Muhammad Luthfi Hamzah ${ }^{1}$, Ermina Rusilawati $^{2}$, Astri Ayu Purwati ${ }^{3}$ \\ Stikom Pelita Indonesia ${ }^{1}$, STIE Pelita Indonesia ${ }^{1,2,3}$ \\ luthfi_hamzah@lecturer.pelitaindonesia.ac.id ${ }^{1}$
}

\begin{abstract}
This study discusses the infrastructure facilities management system in universities. The system is designed using Near Field Communication technology that uses an Android smartphone to support the use of this system and also the web using PHP and MYSQLi programming languages for online data storage. The method used in designing this system is the Waterfall model. This system modeling uses the UML language (Unified Modeling Language). This research was conducted at Pelita Indonesia College. The results showed that the use of Infrastructure Facilities System using Android-based NFC technology is easy to use for Staff and Infrastructure Heads in managing their inventory.
\end{abstract}

Keywords : Infrastructure Facilities, Universities, Near Field Communication, Android

\begin{abstract}
ABSTRAK
Penelitian ini membahas tentang sistem manajemen sarana prasarana pada perguruan tinggi. Sistem yang dirancang menggunakan teknologi Near Field Communication yang menggunakan smartphone android untuk mendukung penggunaan sistem ini dan juga web menggunakan bahasa pemograman PHP dan MYSQLi untuk penyimpanan data secara online.Metode yang digunakan dalam perancangan sistem ini adalah Waterfall model. Pemodelansistem ini menggunakan bahasa UML (Unified Modelling Language). Penelitian ini dilakukan pada Perguruan Tinggi Pelita Indonesia. Hasil penelitian menunjukkan bahwa penggunaan Sistem Sarana Prasarana menggunakan teknologi NFC berbasis android mudah digunakan bagi Staff dan Kepala Sarana Prasarana dalam memanajemen inventarisnya.
\end{abstract}

Kata Kunci: Sarana Prasarana, Perguruan Tinggi, Near Field Communication, Android.

\section{PENDAHULUAN}

Perkembangan teknologi saat ini sudah semakin pesat. Dengan perkembangan ini membuat semua kegiatan dalam proses aktivitasnya menggunakan teknologi agar mempermudah dan mempercepat penggunaannya. Semua sektor terkena atas imbas perkembangan teknologi, baik itu di sektor bisnis, sosial, budaya, dan juga pendidikan. Khususnya di era revolusi industri 4.0 membuat semua industri berbasis digital dalam bentuk hubungan antar manusia, mesin, data dan segala sesuatu sudah ada dimanamana yang dikenal dengan IoT dan
Cyber Physical Systems (CPS)(Rojko, 2017).

Di sektor pendidikan telah banyak terjadi perubahan dalam proses kegiatan belajar mengajar dengan adanya teknologi seperti penggunaan teknologi pada media pembelajaran seperti Elearning, sistem informasi akademik, sistem sarana prasarana dan lainnya. Dalam menciptakan persaingan perguruan tinggi bertaraf nasional maupun internasional perlu adanya implementasi teknologi dalam setiap aktivitas akademik yang berguna untuk efektivitas dan efisiensi kerja organisasi. Dalam Peraturan Pemerintah 
(PP) No. 19tahun 2005 tentang Standar Nasional Pendidikan (SNP) menyatakan tentang standar mutu sebagai alat untuk menilai tingkat mutu penyediaan, pemanfaatan, pemeliharaan, dan pengembangan sarana dan prasarana yangtersedia pada setiap Perguruan Tinggi.

Melihat betapa pentingnya sarana prasarana dalam peningkatan mutu perguruan tinggi, maka beberapa survey pendahuluan telah dilakukan di Perguruan Tinggi Pelita Indonesia Pekanbaru terkait dengan cara pengelolaan sarana prasarana yang dilakukan. Dari hasil survey ditemukan beberapa hal sebagai berikut : Pengelolaan sarana prasarana masih dilaksanakan secara manual (dengan menggunakan catatan kertas yang ditempelkan pada dinding ruangan). Dikarenakan pengelolaan yang masih manual tersebut pendataan masingmasing sarana prasarana sangat tidak efektif. Sebagai contoh tidak adanya data terkait umur sarana prasarana tersebut dan kelayakannya. Perlu adanya sebuah sistem berbasis teknologi yang memudahkan setiap orang melakukan Pengelolaan terhadap sarana prasarana tersebut selain itu membuat kerja organisasi lebih efisien.

Berdasarkan dari permasalahan tersebut, sebuah perancangan teknologi keatas pengelolaan sarana prasarana perlu dilakukan. Teknologi yang umum digunakan dalam pengelolaan atau Pengelolaan adalah RFID (Radio frequency identification) yang berfungsi untuk melakukan suatu identifikasi suatu objek. Perangkat RFID sering kali disebut sebagai tag RFID yaitu mikrochip kecil yang dirancang untuk transmisi data nirkabel. Ini umumnya menempel pada antena dalam paket yang menyerupai stiker perekat biasa. Mikrochip itu sendiri bisa sekecil butiran pasir, sekitar $0,4 \mathrm{~mm}$ (Takaragi dkk, 2001). Menurut Trivedi (2015) Near Field Communication (NFC) merupakan teknologi yang terbaru dari RFID karena NFC adalah bagian dari RFID yang mana teknologi ini merupakan satu konsep yang bisa mempermudah bertransaksi, bertukar data, dan juga melakukan suatu koneksi tanpa menggunakan perantara kabel dengan jarak yang dekat sekitar beberapa sentimeter antar dua perangkat komunikasi dengan prinsip induksi medan magnetic (Trivedi, 2015).

Manajemen adalah suatu proses bagaimana mengkoordinir suatu kegiatan dengan baik untuk dapat menghemat, mengefisiensi suatu kegiatan dalam suatu organisasi dan juga keefektifan suatu pekerjaan yang sedang dilaksanan sudah tepat. Yang dimaksud efisensi disini adalah bagaimana menghemat suatu hal yang besar menjadi sedikit.Sedangkan efektivitas tersebut bagaimana pekerjaan yang dilakukan itu sudah tepat dengan sasaran tujuan(Robbins S.dan Coulter M., 2007). Sedangan menurut Heene A. dan Desmidt S., (2010) Manajemen adalah suatu rangkaian kegiatan seseorang yang berkesinambungan dalam mencapai suatu tujuan dan sasaran yang telah ditetapkannya.

Manajemen sarana prasarana sebagaimana di atur dalam sistem penjaminan mutu perguruan tinggi tahun 2010 standar VIII. Berikut merupakan kelompok Standar Sarana dan Prasarana berdasarkan praktek baik pada beberapa Perguruan Tinggi: Standar Prasarana dan Sarana bangunan, kesehatan serta ketenangan lingkungan; Standar Prasarana dan Sarana fasilitas pembelajaran (di dalam dan di luar ruang); Standar Prasarana dan Sarana sumber belajar (learning resources); Standar pengadaan, pengoperasian, perawatan dan 
perbaikan alat; Standar prasarana umum berupa air, listrik, dan telefon.

\section{METODE PENELITIAN}

Metode yang digunakan dalam penelitian ini adalah SDLC (System Development Life Cycle) Waterfall (Jogiyanto, 2010). Metode ini memiliki pendekatan secara sisitematis mulai dari analisis kebutuhan sistem lalu analisis, desain coding, testing dan maintance, didalam pendekatan ini harus dilakukan secara berurut mulai dari tahap awal sampai akhir :

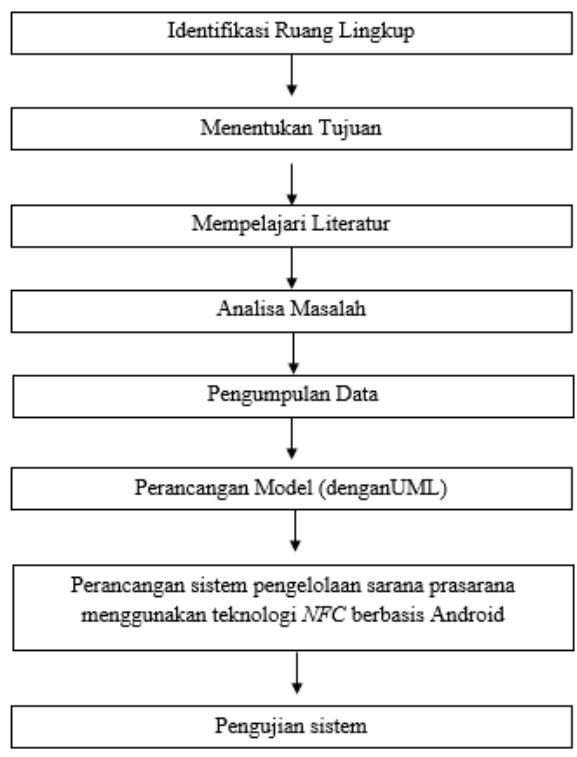

Gambar. 1 Waterfall Model

\section{Identifikasi Ruang Lingkup}

Dalam tahapan ini adalah langkah awal dalam melakukan penelitian ini yaitu membuat ruang lingkup penelitian agar dapat membatasi scope dalam penelitian ini.

\section{Menentukan Tujuan}

Dalam tahapan ini dimaksudkan untuk menentukan tujuan penelitian agar tepat sasaran.

\section{Mempelajari Literatur}

Dalam melakukan suatu penelitian hampir semuanya diawali dengan melakukan mempelajari penelitian- penelitian terdahulu sebagai dasar melakukan penelitian lanjutan.

\section{Analisa Masalah}

Analisa masalah ini merupakan hal penting dalam suatu penelitian agar hasil yang kita dapatkan nanti dapat menjawab dari permasalahan yang kita temukan, oleh sebab itu penelitian ini dilakukan analisa masalah.

\section{Pengumpulan Data}

Selanjutnya adalah pengumpulan semua data terkait dengan masalahmasalah yang akan diselesaikan.

\section{Perancangan Model (UML)}

Perancangan model dalam penelitian ini menggunakan model UML yang merupakan pemodelan berbasis objek. Pemodelan ini berfungsi sebagai blue print dari sistem yang akan dibangun.

\section{Perancangan Sistem}

Pada tahapan ini adalah perancangan sistem yang sesuai dengan pemodelan dengan UML yang telah dibuat, dalam tahap ini dilakukan pengkodingan.

\section{Pengujian Sistem}

Langkah yang terakhir sebelum sistem launching maka harus dilakukan pengujian terlebih dahulu untuk mengetahui bug ataupun kesalahankesalahan yang dapat diperbaiki sebelum sistem diluncurkan.

\section{HASIL DAN PEMBAHASAN Desain Sistem}

Perancangan sistem sarana prasarana perguruan tinggi ini dirancang menggunakan alat bantu berupa UML (Unifield Modelling Language) agar mempermudah memindahkan konsep yang dirancang ke dalam bentuk program, dimana perancangannya 
digambarkan dalam bentuk diagramdiagram berikut :

\section{Use Case Diagram}

Berikut Use Case Diagram Sistem Sarana Prasarana Perguruan Tinggi Menggunakan NFC berbasis Android :

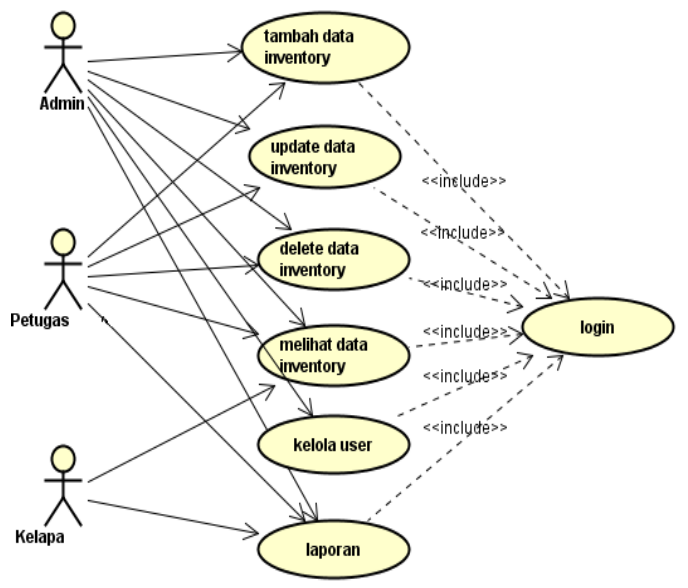

Gambar. 2 Use Case Diagram Sistem Sarana Prasanadengan Menggunakan NFC berbasis Android

\section{Sequence Diagram}

Sequence diagram memperlihatkan tahap demi tahap apa saja yang harus terjadi untuk menghasilkan suatu interaksi di dalam use case diagram.

a. Sequence Diagram Login

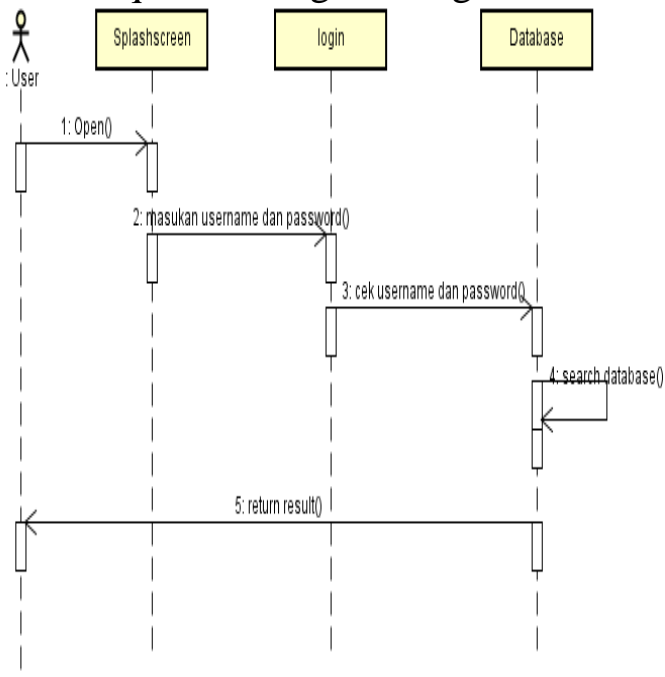

Gambar. 3 Sequence Diagram Login b. Sequence Diagram Tambah Data Inventori

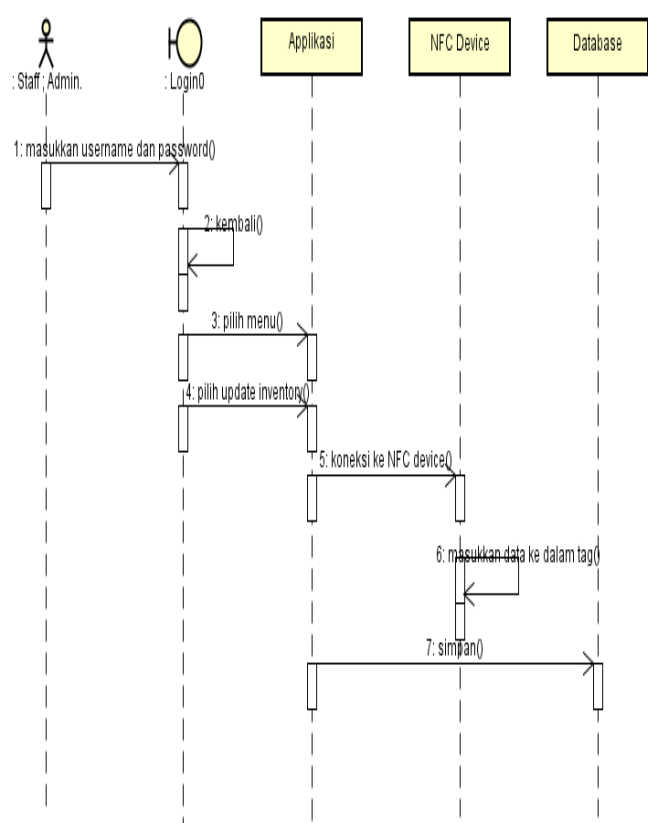

Gambar. 4 Sequence Diagram Tambah Data Inventori

c. Sequence Diagram Update Data Inventori

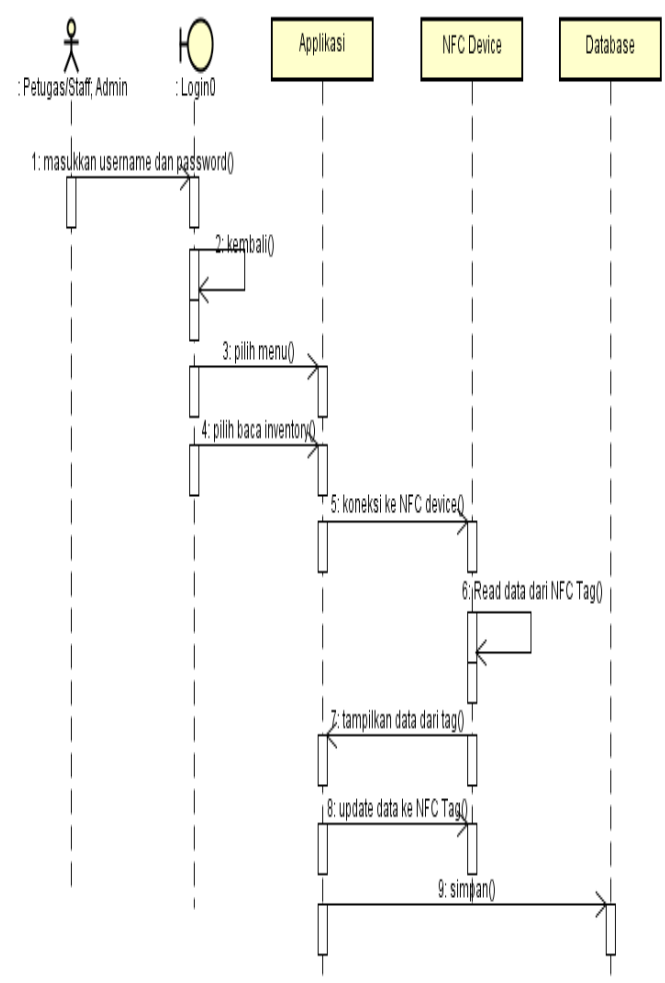

Gambar. 5 Sequence Diagram Update Data Inventori 
d. Sequence Diagram Hapus Data Inventori

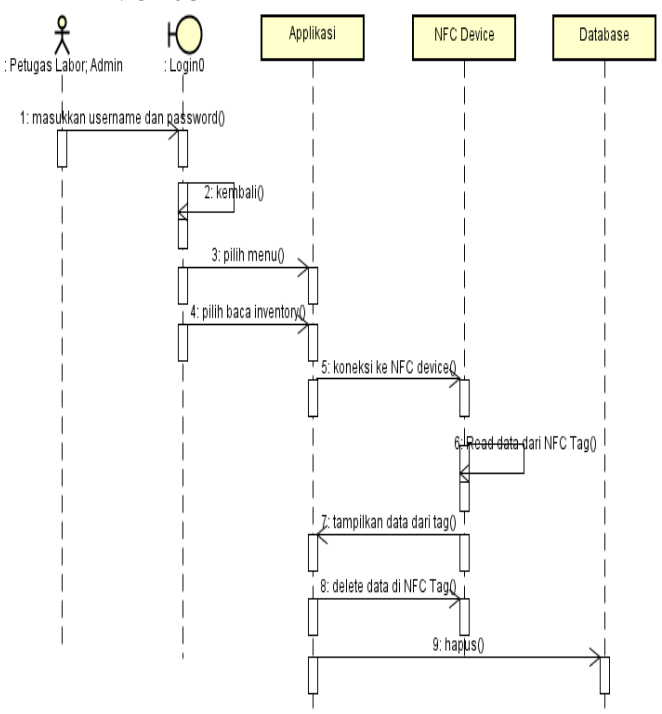

Gambar. 6 Sequence Diagram Hapus Data Inventori

\section{Activity Diagram}

Diagram ini menggambarkan aktifitas-aktifitas yang dapat dilakukan oleh user didalam sistem sarana prasarana pada perguruan tinggi. Pada activity diagram di bawah ini dapat kita lihat aktifitas dari user atau pengguna mengakses berbagai konten seperti menambahkan data inventory, lihat data inventory, update data inventory, delete data inventory, laporan, dan kelola user.

a. Activity Diagram Admin

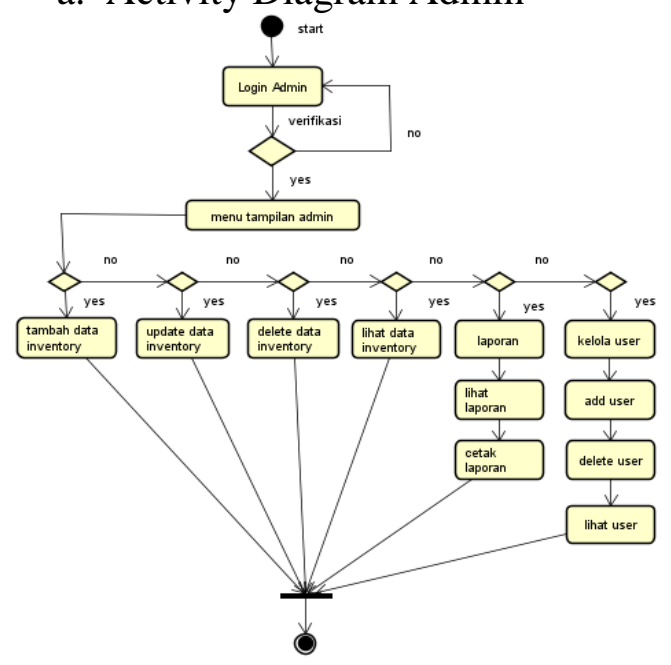

Gambar. 7 Activity Diagram Admin b. Activity Diagram Petugas/Staff

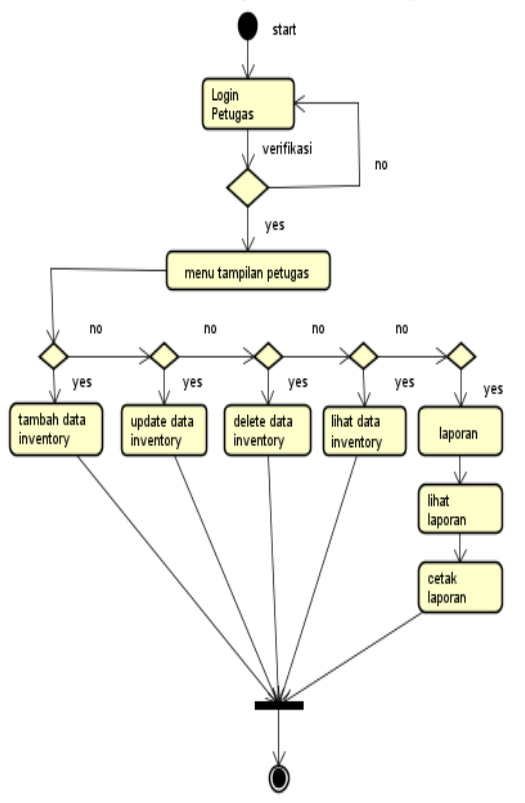

Gambar. 8 Activity Diagram Petugas

c. Activity Diagram Kepala Sarana Prasarana

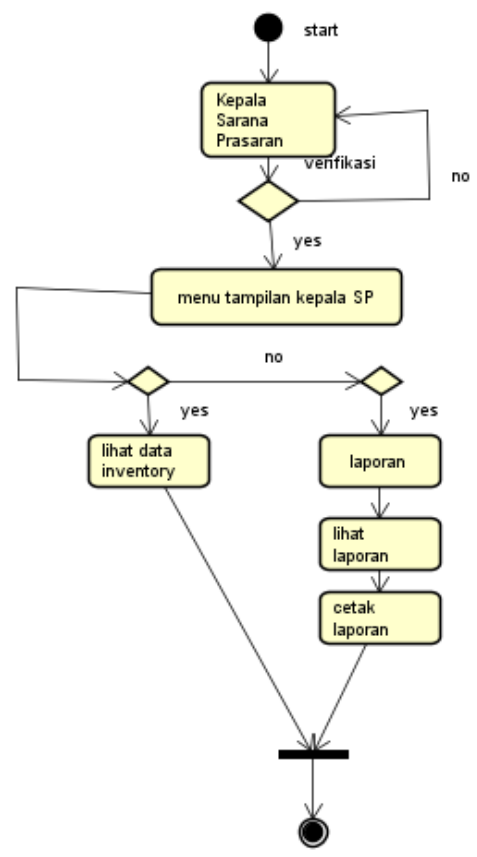

Gambar. 9 Activity Diagram Kepala Saran Prasarana

\section{Class Diagram}

Berikut gambar 10 Class Diagram sistem sarana prasarana perguruan tinggi menggunakan teknologi NFC berbasis Android: 


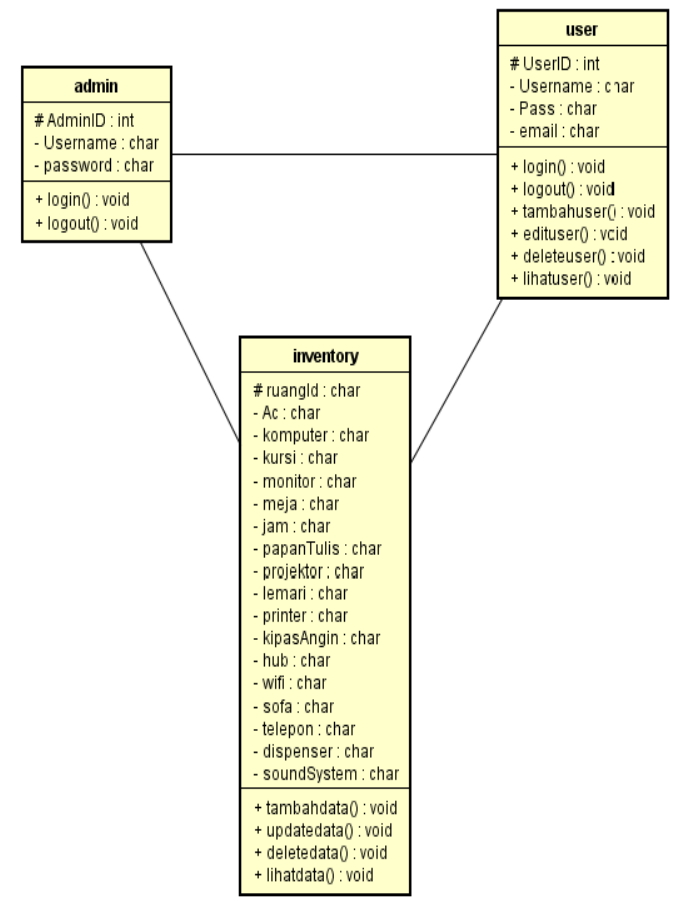

Gambar. 10 Class Diagram

\section{Implementasi Sistem}

\section{Tampilah Splash Screen}

Halaman splash screen adalah tampilan tungguyang pertama muncul waktu aplikasi pada smartphone dijalankan.

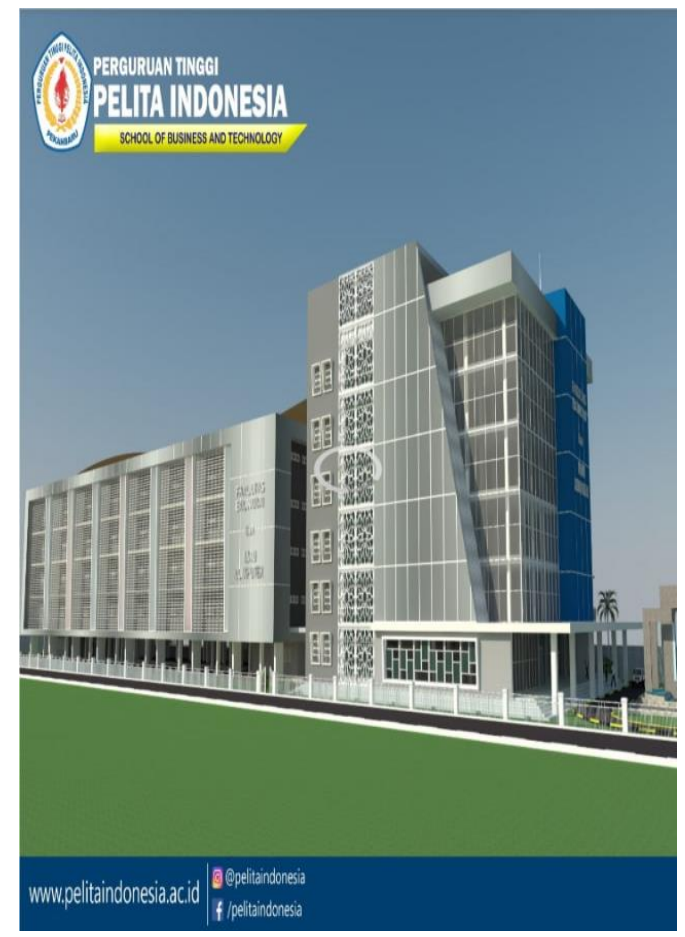

Gambar. 11 Tampilan Splash Screen

\section{Tampilan Halaman Utama}

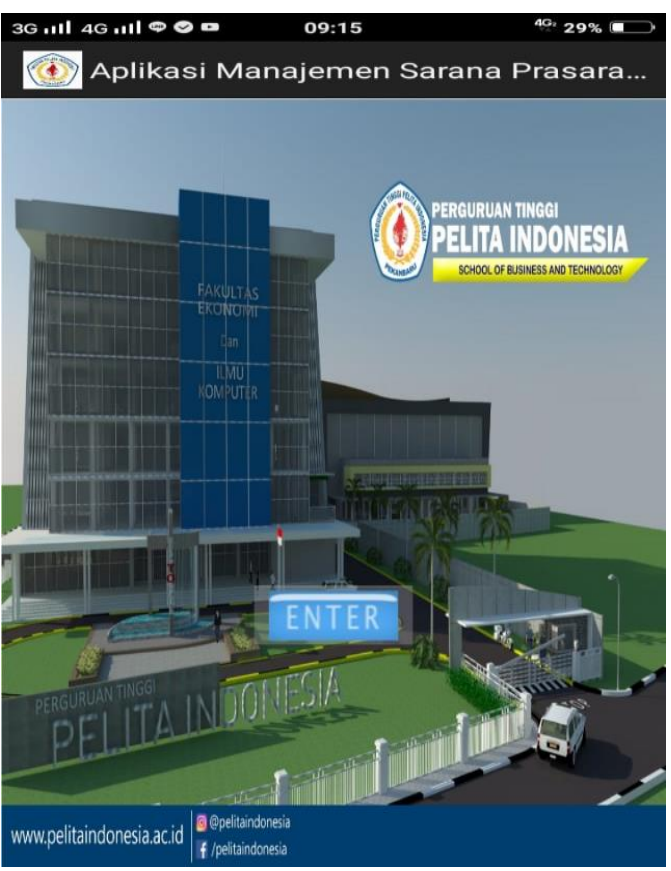

Gambar. 12 Tampilan Halaman Utama

3. Tampilan form Tulis dan Baca NFC Tag

Gambar dibawah adalah tampilan form yang akan user isi berupa data-data spesifikasi sarana prasarana yang akan dimasukkan ke dalam NFC tag

\section{Aplikasi Manajemen Sarana Prasarana}

Scan the NFC tag on the computer for information on its internals. Use the editable text fields below to make changes and click the update button to re-flash the NFC tag.

Ruang Id 1
Meja
Jam
Papan Tulis
Projektor
Lemari
Printer

Gambar. 13 Tampilan Halaman Inventori 
Gambar diatas terlihat bahwa form sarana prasarana akan user isi ke dalam NFC tag dan database, kemudian user akan menempelkan smartphone androidnya ke NFC Tag. Berikut tampilan tulis data ke dalam NFC tag seperti gambar dibawah ini:

\section{Ready to write to NFC tag! \\ Touch your device to a computer's \\ tag to update its inventory. \\ Cancel \\ Gambar. 14 Tampilan Tulis Data ke Dalam NFC tag}

Kemudian berikut tampilan ketika smartphone android membaca NFC tagke dalam sistem seperti gambar dibawah ini :

\section{New inventory tag found!}

Read tag and replace currently displayed tag information in the textfields?

No

Yes

Gambar. 15 Tampilan Baca Data dari NFC Tag

\section{Halaman Login Pada Website}

Halaman Login merupakan halaman dimana user memasukkan username dan password agar dapat masuk ke dalam. Pada gambar 21 dibawah ini tampilan halaman login pada sistem ini :

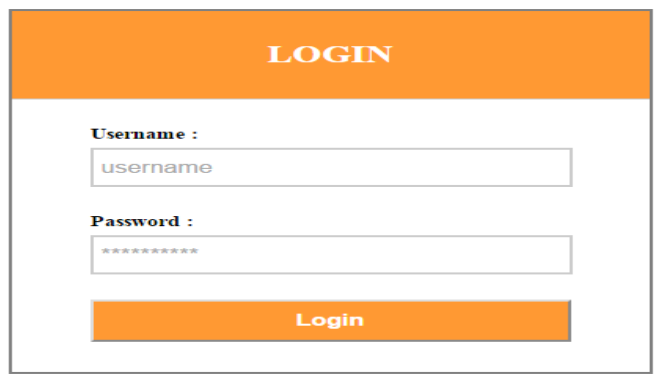

Gambar. 16 Tampilan Halaman Login

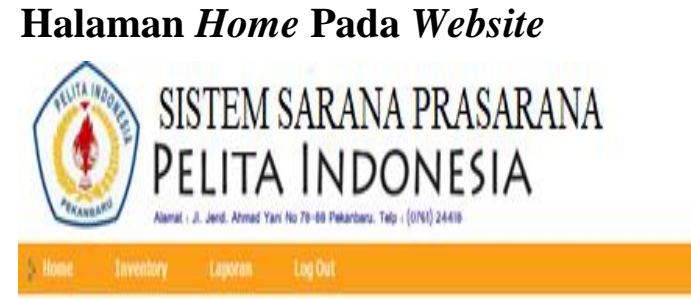

Welcome to ITS Pelita Indonesia

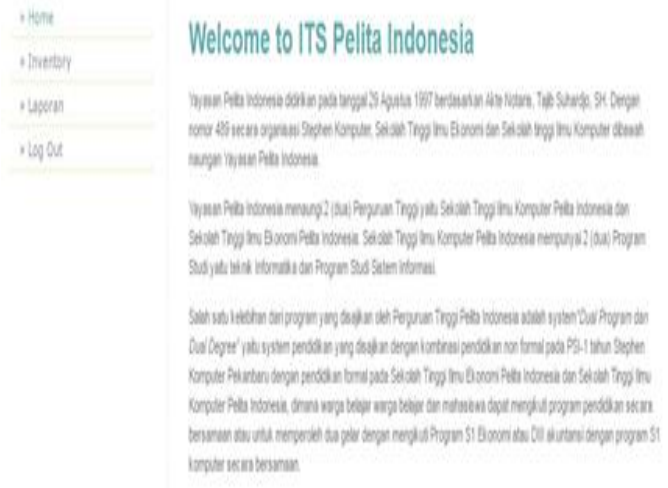

\section{Gambar. 17 Halaman Home}

\section{Smartphone Android}

Smartphone adalah telepon genggam pintar yang mempunyai kemampuan tingkat tinggi yang fungsinyaseperti komputer.Setiap smartphone mempunyai sistem operasi dalam beroperasi seperti Android, IOS, dan lainnya. Androidmerupakan sistem operasi pada smartphone yang berbasis Linux. Android menyediakan platformopensource bagi para developer untuk membuat aplikasi smartphonesendiri. Teknologi saat ini sangat berdampak kepada kehidupan sehari-hari, contohnyamasyarakat sekarang menggunakansmartphone untuk menjadi sarana komunikasi, berbelanja online, mencari informasi, membeli tiket, dan lainnya karena mereka yang sudah menganggap telepon genggamnya sebagai komputer kecil yang bisa dibawa kemana-mana. Hal itu sesuai dengan kemampuan, motivasi, keinginan serta kebutuhan 
masyarakat terhadap kegunaan dari smartphone(Juraman S. R., 2014).

Kebanyakan smartphone sekarang dilengkapi dengan beberapa sensor yang dapat digunakan untuk meningkatkan dan membuat pengguna antarmuka baru. Ini adalah kasus untuk kamera terintegrasi yang dapat digunakan untuk membaca kode visual, seperti Quick Response $(Q R)$ Code serta teknologi penginderaan lainnya seperti Radio Frequency Identification (RFID) dan Near Field Communications terkait (NFC). Penggunaan Kode QR dan tag RFID telah berkembang secara signifikan dalam dekade terakhir, mereka pertama kali digunakan untuk melacak produk di industri, tapi sekarang mereka telah memberikan kontribusi untuk mengembangkan beberapa konsep baru yang mengintegrasikan dunia fisik dengan satu virtual (Briseno et al, 2012).

\section{Radio Frequency Identification}

Pengumuman Wal-Mart pada Juni 2003 bahwa ia berkomitmen untuk sistem RFID meningkatkan pengembangan teknologi (Fanberg, 2004). RFID dapat secara dramatis mengubah kemampuan organisasi untuk mendapatkan informasi real-time di lokasi dan properti orang atau objek yang ditandai. Saat ini RFID telah digunakan di banyak area, seperti lomba marathon, pelacakan bagasi penerbangan, kunci keamanan elektronik, pengumpulan tol, dan pelacakan aset (Angeles, 2005). Ini dianggap sebagai revolusi berikutnya dalam manajemen rantai pasokan

RFID adalah metode Automatic Identification and Data Capture (AIDC) yang menggunakan gelombang radio untuk menyimpan dan mengambil data dari chip identifikasi. Chip ini dikenal sebagai tag RFID. RFID sekarang banyak digunakan di industri untuk beberapa aplikasi termasuk keamanan, kontrol akses, transportasi dan Pengelolaan rantai pasokan. Biasanya sistem RFID memerlukan tiga komponen utama: reader / writer, tag RFID dan aplikasi perangkat lunak untuk pengolahan informasi (Rismawati N., 2016).

\section{Near Field Communication}

Smartphone pada saat ini sudah banyak terintegrasi dengan teknologi NFC. Teknologi NFC ini merupakan subset dari teknologi RFID dan bluetooth. NFC adalah teknologi wireless yang memiliki frekuensi tinggi (13.56 MHz) yang memiliki kecepatan transfer data $424 \mathrm{Kbits} / \mathrm{second}$ dengan jarak jangkauan dekat sekitar beberapa sentimeter. Teknologi NFC merupakan gabungan antara smartcard dan smartcard reader yang ditanam di dalam satu perangkat seperti pada smartphone. Dengan adanya perangkat NFC yang ditanam di dalam sebuah smartpohne, maka kegiatan transaksi seperti pembayaran dapat dilakukan dengan caramenempelkan perangkat NFC ini ke perangkat NFC, smartcard atau smartcard reader yang berada di point of sales transaksi tersebut. Dengan adanya fitur seperti ini maka NFC disebut sebagai perangkat yang mendukung "contactless transaction" (Rismawati N., 2016).Begitu juga dengan Hamzah dan Purwati (2017) yang membuat aplikasi pada Smartphone Android yang tertanam teknologi NFC dalam melakukan pelacakan inventori pada laboratorium komputer di Perguruan Tinggi.

Sebuah perangkat mobile $N F C$ enabled harus memiliki hardware yang sesuai, itu termasuk satuan frekuensi radio, prosesor baseband dan Controller NFC dengan antena. Ini juga termasuk sebuah chip smartcard aman dikenal sebagai elemen aman yang dapat 
digunakan untuk modetag emulasi yang memungkinkan perangkat mobile untuk digunakan sebagai kartu pintar. Ini berarti bahwa ponsel NFC-enabled dapat beroperasi dalam mode berikut seperti yang digambarkan pada gambar dibawah ini (Briseno et al,2012):

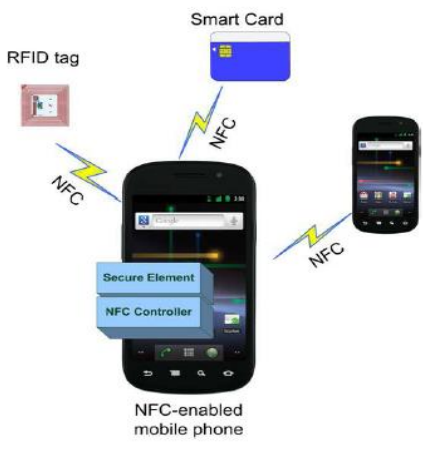

Gambar. 18 NFC Pada Smartphone

\section{Mode Emulasi Kartu}

Pada mode emulasi kartu di mana perangkat NFC berperilaku dengan cara yang sama sebagai tag daripada generator lapangan. Mode ini digunakan untuk memungkinkan pembayaran contactless, di mana media pembayaran menggunakan telepon hanya melambaikan dekat perangkat penerima untuk memulai transaksi.

\section{Mode Pembaca / Penulis NFC}

Pada mode ini, induk NFC dapat membaca / menulis tag NFC. Contohnya adalah membaca informasi berguna dari poster pintar.

\section{Mode Peer To Peer}

Sebuah perangkat yang dilengkapi NFC dapat digunakan sebagai modus Peer-to-Peer dengan memungkinkan dua pengguna untuk bertukar informasi antara perangkat mereka seperti playlist musik, kontak, dan bahkan data medis.
Ada empat kategori bagaimana cara NFC bekerja, yaitu (Al-Ofeishat dan Rababah., 2012):

1. Telepon ke telepon

Dalam kategori ini dua ponsel dilengkapi dengan NFC berkomunikasi satu sama lain. Mereka dapat mentransfer file musik atau gambar hanya dengan menyentuh satu sama lain.

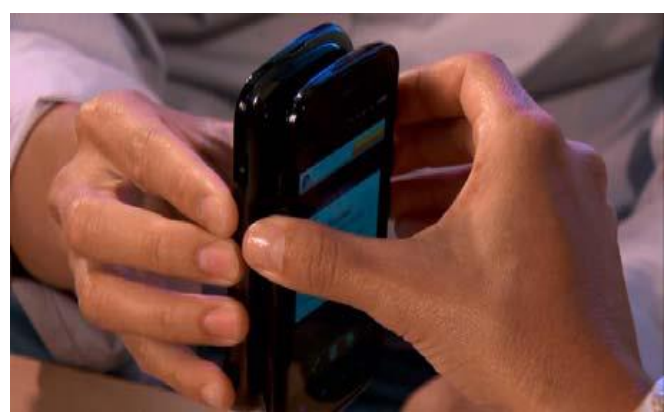

Gambar. 19 Telepon ke Telepon Transaksi Menggunakan NFC

2. Telepon ke perangkat

Berikut ponsel NFC dilengkapi dapat berkomunikasi dengan perangkat apapun. Misalnya, dengan hanya menyentuh telepon dengan printer NFC dilengkapi dapat mencetak gambar yang disimpan dalam ponsel. Atau dengan menyentuh perangkat pembayaran dapat melakukan transaksi pembayaran.

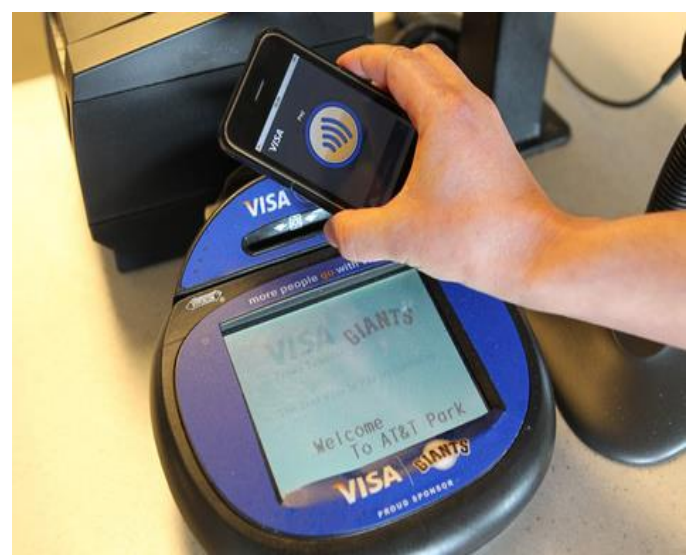

Gambar. 20 Telepon ke Perangkat Transaksi 
3. Telepon ke tag

Tag ini berisikan data dan biasanya tertanam di poster atau tujuan pemasaran. ponsel disentuh dengan tag dan data dari tag ditransfer ke ponsel.

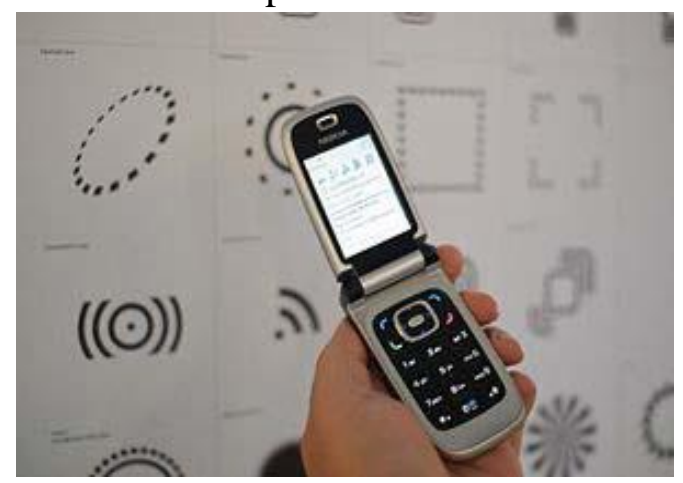

Gambar. 21 Telepon ke Tag

4. Telepon untuk pembaca (reader)

Kita bisa membeli dan menyimpan tiket elektronik pada ponsel kita. ponsel dapat berkomunikasi dengan pembaca eksternal hanya dengan menyentuh dengan pembaca. Sehingga orang dapat membeli tiket dengan mudah tanpa berdiri dan menunggu dalam antrian panjang.

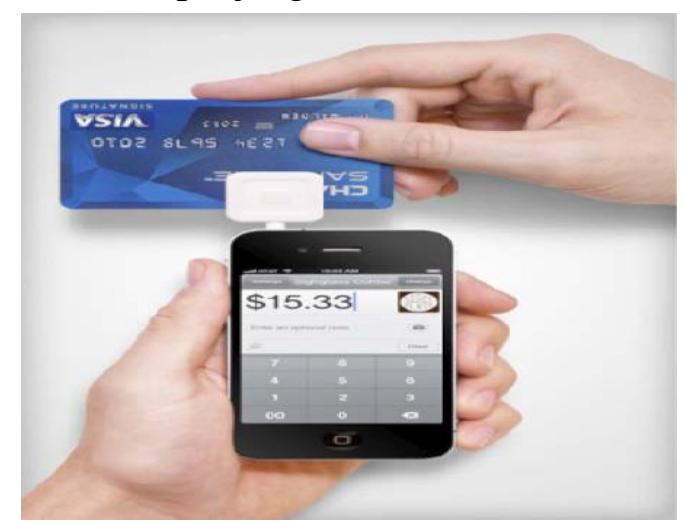

Gambar. 22 Telepon ke Reader Transaksi

\section{SIMPULAN}

Berdasarkan perancangan dan pembuatan sistem manajemen sarana prasrana perguruan tinggi menggunakan NFC berbasis android maka dapat simpulkan bahwa :
1. Perencanaan dan pemodelan manajemen sistem sarana prasarana perguruan tinggi menggunakan teknologi NFC memudahkan dalam pengidentifikasian informasi setiap Sarana Prasarana Perguruan Tinggi Pelita Indonesia .

2. Sistem yang dirancang menggunakan NFC pada smartphone android dapat membantu memudahkan user dalam pencapaian suatu informasi agar lebih efektif dan efisien.

\section{DAFTAR PUSTAKA}

Al-Ofeishat, H. A., \& Rababah,. (2012). Near Field Communication (NFC). International Journal of Computer Science and Network Security, 12(2), 93-99

Angeles, R. (2005). RFID Technology: Supply-Chain Applications and Implementations Issues. Information Systems Management, 22(1), 51-65

Briseno, M. V., Hirata, F. I., Lopez, J. D. S., Garcia, E. J., Cota, C. N., \& Hipolito, J. I. N. (2012). Using RFID/NFC and QR-Code in Mobile Phones to Link the Physical and the Digital World. Mexico: University of Baja California

Fanberg, H. (2004). The RFID Revolution. Marketing Health Services, 24(3), 43-44

Hamzah, M. L., \& Purwati, A. A. (2017). Sistem Manajemen Inventori Komputer Menggunakan Near Field Communication Berbasis Android (Studi Kasus di STIE Pelita Indonesia Pekanbaru). Journal of Business and Accounting (COSTING), 1(1), 95-104

Hazura H. (2009). RFID Based Laboratory Management System. Malaysia: Faculty of Electronics and Computer Engineering, 
Universiti Teknikal Melaka. Malaysia. 2009 International Conference on Computer Technology and Development, 2, 289-29

Heene, A., \& Desmidt, S. (2010). Manajemen Strategik Keorganisasian Publik. Bandung: PT Refika Aditama

Jogiyanto, J. (2010). Analisis dan Desain Sistem Informasi. Yogyakarta: Andi Offset

Juraman S. R. (2014). Pemanfaatan Smartphone Android oleh Mahasiswa Ilmu Komunikasi dalam Mengakses Informasi Edukatif. Jurnal Unstrat 3(1)

Kementrian Pendidikan Nasional. (2010). Sistem Penjaminan Mutu Perguruan Tinggi Tahun 2010. Direktorat Jendral Pendidikan Tinggi. Jakarta

Rismawati, N. (2016). Sistem Absensi Dosen Menggunakan Near Field Communication (NFC) Technology. Fakultas Teknik, Matematika dan Ilmu Pengetahuan Alam. Universitas Indraprasta PGRI. Jurnal Faktor Exacta, 9(2), 135-142

Robbins S. \& Coulter M. (2007). Manajemen, Edisi Kedelapan. Jakarta: Penerbit PT Indeks

Rojko, A. (2017). Industry 4.0 Concept: Background and Overview. International Journal of Interactive Mobile Technology, 11(5), 77-90

Rung, S. C., \& Chia, P. L. (2015). NFC Based Equipment Inventory System. Departement of Computer Science and Information Engineering National Kaosiung University of Applied Sciences. Journal of Information Hiding and Multimedia Signal Processing, 6(6), 1145-1155
Takaragi, K., Usami, M., Imura, I., Itsuki, R. \& Satoh, T. (2001). An Ultra Small Individual Recognition Security Chip. IEEE Micro, 21(6), 42-49

Trivedi, D. (2015). Near Field Communication: Overview and Applications. India. International Journal of Engineering Development and Research (IJEDR),3(3), 1-12 